\title{
Comportamento ingestivo de éguas e potros da raça Crioula em campo nativo melhorado
}

\section{Ingestive behavior of mares and foals of the Crioulo breed in improved native field}

João Danilo Biffi Pereira, Marcele Sousa Vilanova*, Caroline Braga Andelieri, Cátia Dal Bello Giacomet, Willian Perin

Universidade de Caxias do Sul (UCS), Caxias do Sul, RS, Brasil

\section{Resumo}

O objetivo deste trabalho foi avaliar o comportamento ingestivo de éguas da raça Crioula, prenhas e com potro ao pé, em pastagem de campo nativo melhorado, durante os turnos da manhã, meio-dia e tarde. 0 experimento foi realizado na Cabanha Tamboré, localizada no município de São Francisco de Paula, no estado do Rio Grande do Sul. Foram selecionadas oito éguas com idade média de 9 anos, prenhas, com potros ao pé. Os animais foram alocados em um potreiro de 8 ha, composto por pastagem nativa, melhorada com trevo branco, trevo vermelho e cornichão. Foram avaliados três tratamentos: turno da manhã, turno do meiodia e turno da tarde, durante o período das $8 \mathrm{~h}$ às $18 \mathrm{~h}$, compreendendo dez horas totais de avaliação. A coleta dos dados foi realizada em três dias consecutivos. Foram anotadas as frequências dos comportamentos ingestivos e a interação entre os animais égua/égua, égua/potro e potro/potro. 0 método de avaliação utilizado foi o do etograma, técnica de amostragem do animal focal, com intervalos de 10 em 10 minutos entre as observações. 0 delineamento experimental foi inteiramente casualizado, com 24 repetições de cada tratamento (para potros e para éguas, distintamente). Os resultados obtidos foram submetidos à análise de variância e as médias comparadas pelo teste $\mathrm{t}$ a $5 \%$ de probabilidade. Os três principais comportamentos realizados pelos potros, durante as 10 hs de avaliação, foram dormir, ficar em ócio e pastejar, enquanto as éguas apresentaram como maior frequência os comportamentos de descanso e pastejo. 0 conhecimento das variáveis comportamentais em potros e éguas em pastoreio permite ao criador uma ferramenta para melhor manejar seus animais.

Palavras-chave: Etologia. Bem-estar animal. Pastejo.

\begin{abstract}
The objective of this work was to evaluate the ingestive behavior of mares of the Crioula breed, pregnant and with foal at the foot, in improved native field pasture during the morning, midday, and afternoon shifts. The experiment was carried out at Cabanha Tamboré, located in the municipality of São Francisco de Paula, in Rio Grande do Sul state. Eight mares with a mean age of 9 years, and pregnant, were selected with foals at the foot.
\end{abstract}


The animals were allocated in a pasture of 8 ha, composed of native pasture, improved with white clover, red clover and Lotus corniculatus. Three treatments were evaluated: morning shift, midday shift and afternoon shift, during the period from 8 am to 6 pm comprising ten total hours of evaluation. Data were collected on three consecutive days. The evaluated variables were differentiated for mares and foals, and different evaluations were performed for each category, through specific tables, in which the frequencies of ingestive behaviors and the interaction between mare/ mare, mare/foal and foal/foal. The evaluation method used was the etogram, focal animal sampling technique, with 10/10 minute intervals between observations. The experimental design was completely randomized, with 24 replicates of each treatment (for foals and for mares, distinctly). The results were submitted to analysis of variance and the means compared by the T test (5\% probability). The three main behaviors performed by the foals during the 10-hour evaluation were sleeping, idling and grazing, while mares showed more frequent resting and grazing behaviors. Knowledge of behavioral variables in foals and herds in grazing allows the breeder a tool to better manage their animals.

Keywords: Ethology. Animal welfare. Pasture.

\section{Introdução}

O cavalo doméstico é classificado como monogástrico, pastejador de vegetais e consumidor de uma grande variedade de alimentos (Frape, 2008), muito em função do processo de domesticação com base nas pastagens naturais, as quais possuíam uma composição rica em diferentes espécies vegetais, proporcionando aos animais grande capacidade de escolha (Churcher, 1993).

Com a domesticação, houve a interferência do homem, causando redução das variedades de espécies forrageiras oferecidas na dieta dos animais (Illius et al., 1992). A adequação do ambiente pastoril pode disponibilizar muito mais do que nutrientes, pois permite a liberdade aos animais para expressarem o comportamento natural da espécie, evitando mudanças comportamentais e, consequentemente, alterações em seu bem-estar (Dittrich et al., 2007).

0 estudo do comportamento ingestivo dos equinos pode nortear a adequação de práticas de manejo que venham a aumentar a eficiência de trabalho e reprodução de éguas, além de garantir o melhor estado sanitário e longevidade aos animais (Frape, 2008), uma vez que avalia os tempos despendidos com as atividades de pastejo, ócio, mastigação, caminhada e ingestão de água (Fischer et al., 1998).

A observação do pastejo, processo em que os animais levam a forragem à boca, prendem-na entre os dentes e cortam-na com o movimento da cabeça (Cosgrove, 1997), é uma das mais importantes por estar diretamente relacionada com a ingestão de nutrientes pelo animal.

Os fatores climáticos como temperatura e umidade relativa do ar, principalmente durante o verão, influenciam diretamente no comportamento ingestivo dos animais (Moreira Filho et al., 2008). 0 conhecimento dessas variáveis durante os turnos do dia, correlacionando com os hábitos alimentares dos equinos, pode contribuir para o bem-estar e para o desempenho mais eficaz dos animais.

Nas últimas duas décadas, estudos sobre a importância do bem-estar animal vêm crescendo consideravelmente, uma vez que a conscientização de diversos profissionais e da população mundial sobre a capacidade senciente dos animais está cada vez mais forte (Broom e Fraser, 2010).

Quando há sinais de bem-estar precários, os animais tendem a desenvolver comportamentos estereotipados (alterados e sem função aparente), o que resulta em menor produtividade e faz com que esses animais mudem toda a sua rotina para se adaptarem aos desafios de ambientes inadequados (Broom e Molento, 2004). Ainda hoje, pouco se conhece sobre a interação do comportamento dos equinos com o ambiente disponibilizado pelos homens a esses animais, e sobre a relação das éguas com suas crias nesses mesmos ambientes.

Frente a essa importância, o objetivo deste trabalho foi avaliar o comportamento ingestivo de éguas prenhas e de seus potros em pastagem de campo nativo melhorado. 


\section{Material e métodos}

O trabalho foi realizado na Cabanha Tamboré, localizada no município de São Francisco de Paula, em latitude de $29^{\circ} 04^{\prime} \mathrm{S}$ e longitude de $50^{\circ} 42^{\prime} \mathrm{W}$. O clima durante os três dias de avaliação variou entre 27 e $27,5^{\circ} \mathrm{C}$, e a umidade relativa do ar média compensada foi de $80 \%$ (INMET, 2017). 0 período experimental compreendeu três dias consecutivos de avaliações, durante o mês de janeiro (verão), com o objetivo de evitar variação nas características climáticas que influenciam o comportamento dos animais.

Foram selecionadas oito éguas com seus potros (com aproximadamente 5 meses de idade), da raça Crioula, com idade média de 9 anos, todas lactantes, gestantes e multíparas, com peso corporal médio de $350 \mathrm{~kg}$. Para facilitar a identificação na hora da avaliação visual da atividade de campo no potreiro, os animais foram identificados por fitas coloridas amarradas no pescoço.

Após selecionados para o experimento, os animais foram alocados em um potreiro, com área total de 10 hectares, com uma oferta forrageira composta por campo nativo melhorado com trevo branco, trevo vermelho e cornichão.

Foram testadas as diferenças de comportamento ingestivo das éguas e dos seus potros durante três turnos distintos, cada um totalizando 190 minutos: manhã (8h - 11h10), meio-dia (11h20 - 14h30) e tarde (14h40 - 17h50).

0 delineamento experimental foi inteiramente casualizado, com o fator turno (manhã, meio-dia e tarde) como tratamento e 24 repetições de cada tratamento para cada categoria animal (8 éguas x 3 dias de avaliação consecutiva e 8 potros $\mathrm{x} 3$ dias de avaliação consecutiva).

Foram avaliados os comportamentos ingestivos das éguas e dos potros, distintamente, utilizandose a técnica do etograma: animal focal (Del-Claro, 2004), com intervalo de observações de 10/10 minutos, anotados em planilhas individuais.

Foram avaliados os tempos despendidos com os comportamentos de pastejar (ato de colher o pasto), caminhar (deslocamento pelo potreiro), ingerir água, ingerir sal mineral, estar em ócio (tempo em que o animal não está realizando nenhuma atividade), mastigar (ato de triturar o alimento), brincar/exercitar (corridas ou pulos pelo potreiro), coçar (ato de se coçarem em árvores, cochos e até mesmo um no outro), lactar (ato do potro sugar o úbere da égua) e interagir com o potro (contato físico entre os animais).

No comportamento ingestivo dos potros foram avaliados os mesmos comportamentos das éguas, acrescidos dos atos de dormir (tempo despendido deitado com o corpo estendido no chão) e interagir com outro potro (contato físico entre os potros).

\section{Análise estatística}

Os dados foram convertidos em percentuais de tempo (utilizando 60 minutos como 100\%) e os comportamentos gerias foram submetidos à estatística descritiva. Os comportamentos avaliados entre os turnos foram submetidos à análise de variância (ANOVA) e as médias comparadas pelo teste T, utilizando o programa ASSISTAT 7.1 (Silva e Azevedo, 2002).

\section{Resultados e discussão}

Os três principais comportamentos realizados pelos potros, durante as 10 horas de avaliação, foram pastejar, ócio e dormir, sendo que na idade avaliada (5 meses) a ingestão de leite (mamada) já foi substituída pela ingestão de alimento sólido (pastejo), conforme mostra a Figura 1.

A partir do terceiro mês de lactação, a produção de leite da égua sofre um rápido declínio, o que deixa de ser suficiente para suprir as necessidades nutricionais do potro (Ott, 1986). A partir desse período, portanto, o potro pode apresentar crescimento deficiente se não for oferecido alimento adicional com os nutrientes necessários para suprir o déficit na produção de leite das éguas (Frape, 2008).

No turno da manhã, os potros substituíram a atividade de pastejo pela atividade de dormir, enquanto no turno da tarde o pastejo voltou a ser prioridade (Figura 2).

Na evolução da atividade de pastejo em potros existem duas fases bem distintas. A primeira é a exploratória, que ocorre entre 0 e 60 dias de idade e é caracterizada pela grande diversidade de bocados 
e baixa ingestão de matéria seca, sendo o aporte nutricional nesta fase suprido pela amamentação. A partir dos 2 meses de idade, a atividade de pastejo se intensifica, aumentando a importância deste na nutrição do potro e na ingestão de matéria seca (Frape, 2008).

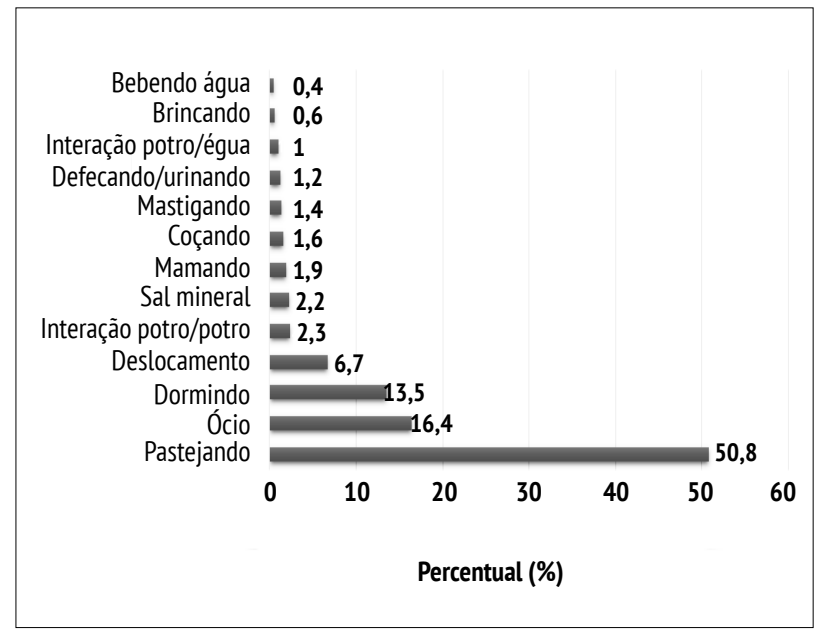

Figura 1 - Distribuição dos percentuais médios gerais dos comportamentos ingestivos dos potros da raça Crioula.

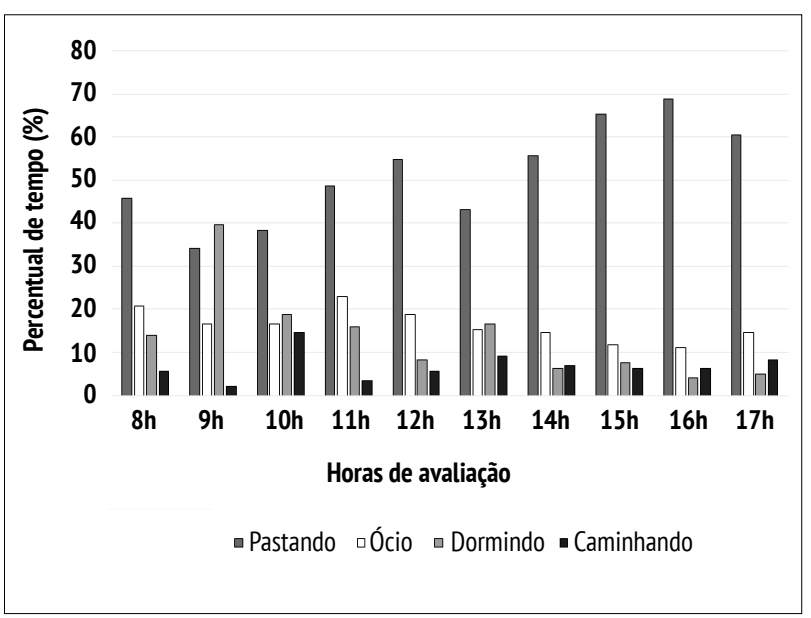

Figura 2 - Distribuição dos percentuais médios dos comportamentos ingestivos dos potros da raça Crioula, correlacionados com as horas de avaliação.

Os únicos comportamentos que sofreram influência do turno, na avaliação dos potros, foram as atividades de pastejar e dormir (Figura 3).

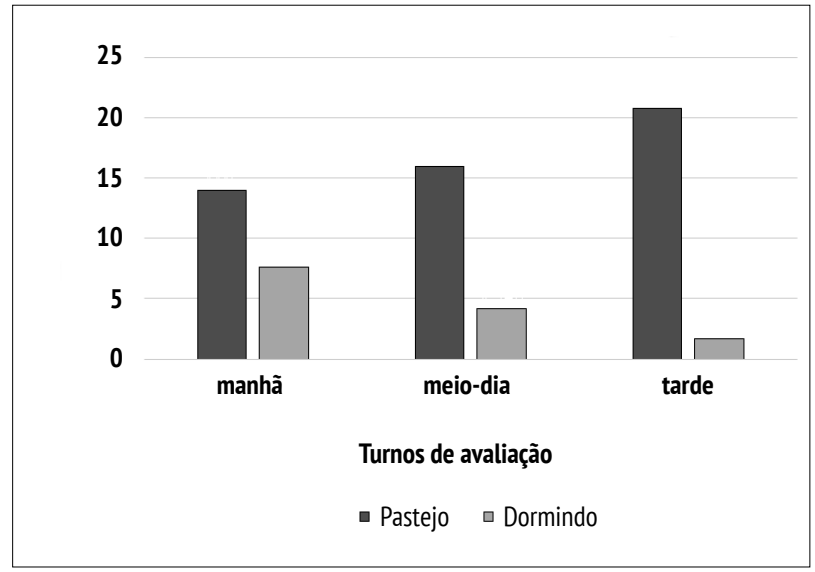

Nota: * Letras maiúsculas distintas indicam diferença significativa $(\mathrm{p}<$ $0,05)$ entre os comportamentos dentro do mesmo turno. Letras minúsculas distintas se referem à diferença estatística $(p<0,05)$ do comportamento entre os turnos.

Figura 3 - Variação percentual média dos comportamentos dos potros, que sofreram influência do turno de avaliação.

Os potros pastejaram mais no turno da tarde, entretanto, distribuíram a intensidade desta atividade entre o tempo de avaliação. Já o comportamento de dormir foi muito menos intenso à tarde, quando comparado ao turno da manhã e meio-dia, uma vez que os animais podem ter suprido as necessidades de sono entre os turnos da manhã e do meio-dia, restando para o turno da tarde a realização de atividades mais intensas com relação à atividade física e gasto de energia.0 ato de dormir é um comportamento muito comum em animais jovens, sendo que o ritmo diário de sono varia muito de um animal para outro. Os potros, entretanto, intensificam essa atividade, intercalando-a entre as demais realizadas durante o dia (Meyer, 1995).

Ao avaliar os comportamentos de interação entre os animais, observou-se que os potros tendem a brincar entre si com maior frequência no início do dia (Figura 4), intercalando as brincadeiras com a ingestão de leite e interação com a égua.

Segundo Pimentel et al. (2017), com o passar da idade do potro, ocorre a diminuição na frequência de interação entre o potro e a égua, sendo que as maiores frequências foram observadas durante os períodos iniciais do desenvolvimento do filhote, em função da dependência e socialização. 
0 conhecimento das atividades realizadas pelos potros aos 5 meses de idade pode ser um indicativo para decisão mais precisa do período de desmame, uma vez que indica a total capacidade do animal em realizar a colheita do alimento e manutenção da nutrição adequada, diminuindo significativamente a dependência do leite materno.

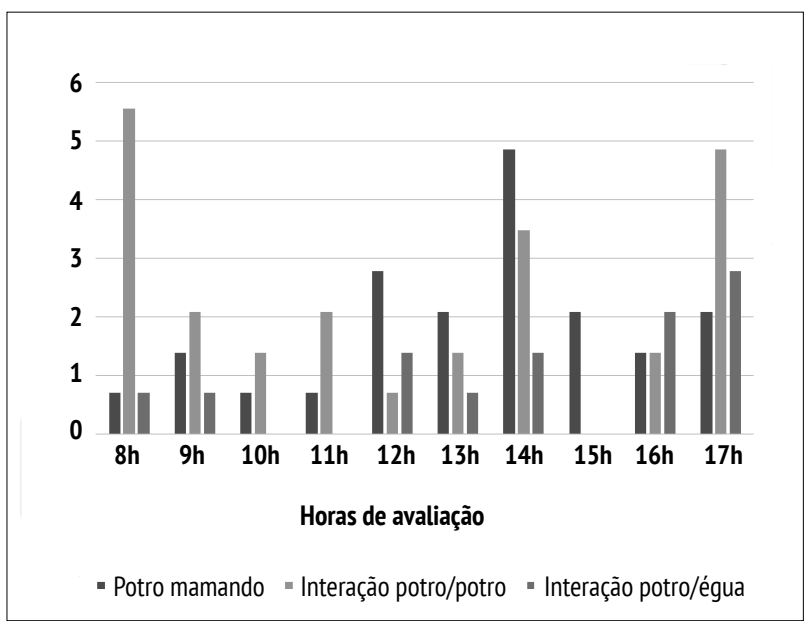

Figura 4 - Variação percentual média dos comportamentos dos potros, que sofreram influência do turno de avaliação.

$\mathrm{Na}$ avaliação do comportamento geral das éguas, estas despenderam mais tempo entre os comportamentos de pastejo e descanso (ócio), conforme indica a Figura 5.

Os equinos utilizam a maior parte do dia com as atividades de ingestão de alimento e descanso, o que, segundo Zanine et al. (2005), representou, em 24 horas de avaliação, 59,5\% do tempo dispendido com o comportamento de pastejo e 40,5\% com descanso e outras atividades.

Na descrição das atividades por hora, observouse que as éguas intercalam, de hora em hora, a atividade de ingestão de alimento com as demais atividades (Figura 6). Em função da ingestão de pouca quantidade de matéria seca, os equinos necessitam de uma elevada frequência de ingestão de alimento, pois uma vez suprida a capacidade ingestiva estomacal, este conteúdo ingerido precisa seguir o trânsito intestinal (saindo do estômago) para possibilitar nova atividade ingestiva (Frape, 2008), o que ficou bem representado na Figura 6.

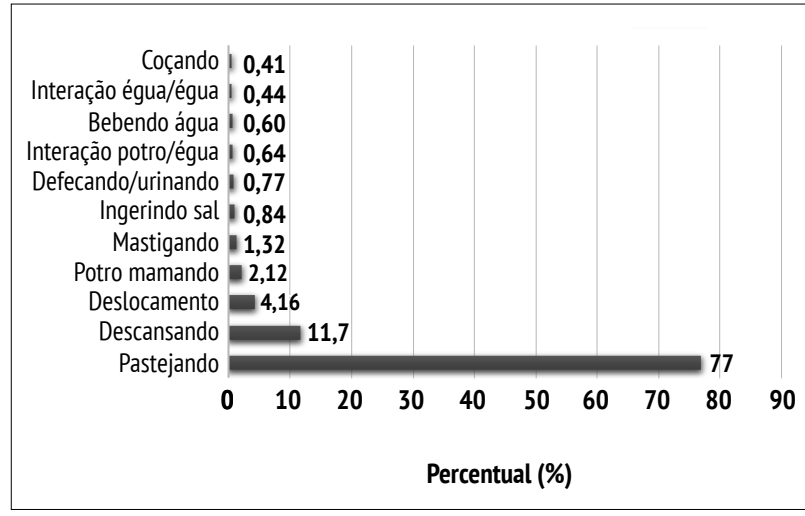

Figura 5 - Distribuição dos percentuais médios dos comportamentos ingestivos das éguas.

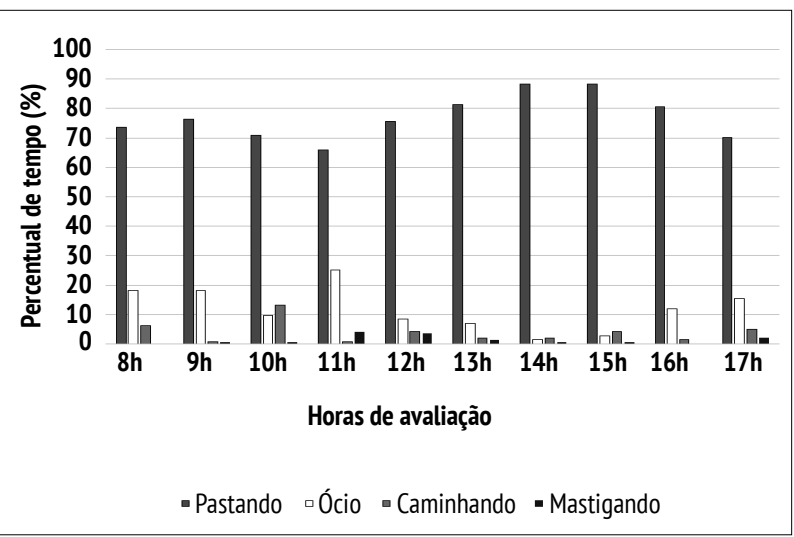

Figura 6 - Distribuição dos percentuais médios dos comportamentos ingestivos que sofreram influência do turno de avaliação no comportamento ingestivo das éguas.

Um cavalo solto a pasto se alimenta, em média, de 18 a 19 horas por dia. Tal frequência será influenciada pelo tipo de alimento fornecido, uma vez que o alimento volumoso, base da dieta dos herbívoros, sofre fermentação quando chega ao intestino grosso (ceco e cólon), onde sofrerá ação da flora intestinal. Uma característica importante é a rápida velocidade de passagem do alimento pelo intestino, o que estimula novos ciclos de alimentação, com média de hora em hora (Broom e Fraser, 2010).

O conhecimento dos ciclos diários de pastejo dos animais é de grande relevância em sistemas de produção a pasto. A definição dos horários em que preferencialmente os animais exercem o pastejo 
orienta o estabelecimento quanto às estratégias adequadas de manejo, enquanto o tempo total gasto no pastejo é fator intimamente relacionado ao consumo voluntário do pasto (Ribeiro et al., 1997).

Uma vez que as éguas intercalaram o comportamento de pastejo de hora em hora, o uso de manejos que as privam de terem acesso ao potreiro por longas horas do dia deve ser reavaliado, principalmente com base em seu bem-estar, pois além da privação da realização de comportamentos naturais, esta prática pode acarretar na incidência de problemas digestivos, prejudicando a saúde e a integridade física destes animais.

\section{Conclusão}

A ingestão de pasto pelos potros aos 5 meses de idade já está em pleno estabelecimento, o que indica a total capacidadedoanimalemserindependentedoleite materno. 0 conhecimento das atividades realizadas pelas éguas gestantes e em lactação pode auxiliar os manejadores na escolha dos melhores períodos de manuseio desses animais e de confinamento quando necessário, visando a busca incessante pelo bem-estar animal nas criações de equinos.

\section{Referências}

Broom DM. Fraser AF. Comportamento e bem-estar dos animais domésticos. 4 ed. Barueri: Manole; 2010. 437 p.

Broom DM. Molento CFM. Bem-estar animal: conceito e questões relacionadas - Revisão. Arch Vet Sci. 2004;9(2):1-11.

Churcher CS. Equus grevyi. Mammalian Species. 1993;(453):1-9.

Cosgrove GP. Grazing behaviour and forage intake. Simpósio Sobre Avaliação de Pastagens Com Animais; Maringá, PR. Maringá: Universidade Estadual de Maringá; 1997. p. 59-80.

Del-Claro K. Comportamento Animal - Uma introdução à ecologia comportamental. Jundiaí: Conceito; 2004. 132 p.
Dittrich JR, Carvalho PCF, Dittrich RL, Moraes A. Comportamento ingestivo de equinos em pastagens. Arch Vet Sci. 2007;12(3):1-8.

Fisher V, Deswysen GA, Dutilleul P, De Boever J. Padrões da distribuição nictemeral do comportamento ingestivo de vacas leiteiras, ao início e ao final da lactação, alimentadas com dieta à base de silagem de milho. R Bras Zootec. 1998;31(5):2129-38.

Frape D. Nutrição e alimentação de equinos. 3.ed. São Paulo: Roca; 2008. 602 p.

Illius AW, Clark DA, Hodgson J. Discrimination and patch choice by sheep grazing grass-clover swards. J Anim Ecol. 1992;61:183-94.

INMET - Instituto Nacional de Meteorologia. Temperatura e umidade relativa do ar da região de São Francisco de Paula/RS. 2017 [acesso 15 nov 2017]. Disponível em: https://tinyurl.com/ybzh27g4.

Meyer H. Alimentação de cavalos. São Paulo: Livraria Varela; 1995.300 p.

Moreira Filho MA, Rodrigue MM, Oliveira ME, Azevedo DMMR, Veras VS, Azar GS. Comportamento de cabras sob pastejo em pastagem mista. 45 a Reunião Anual da Sociedade Brasileira de Zootecnia; 22-25 jul 2008; João Pessoa, PB. João Pessoa: ABZ, 2008.

Ott EA. Problemas associados à alimentação do cavalo. Manejo prático da alimentação dos animais. IV Encontro Nacional de Equideocultura; 1986; São Paulo, SP. São Paulo: Sociedade Brasileira de Hipologia; 1986. p. 26.

Pimentel AMH, Rodrigues WB, Martins CF, Montanez NR, Boligon AA, Souza JRM. O sexo no crescimento de potros da raça Crioula do nascimento aos três anos de idade. Cienc Rural. 2017;47(1):e20150989.

Ribeiro Filho HMN. Almeida EX. Harthmann OEL. Maraschin GE. Tempo e ciclos diários de pastejo de bovinos submetidos a diferentes ofertas de forragem de capim elefante anão cv. 34 ${ }^{\mathrm{a}}$ Reunião Anual da Sociedade Brasileira de Zootecnia; 28 jul -1 ago 1997; Juiz de Fora, MG. 1997. Juiz de Fora: SBZ; 1997. 
Silva faz, Azevedo CAV. Versão do programa computacional Assistat para o sistema operacional Windows. Rev Bras Prod Agroind. 2002;4(1):71-8.

Zanine AM, Ferreira DJ, Santos EM, Parente HN. Hábito de pastejo de equinos em pastagens de tifton 85 (Cynodon ssp) no nordeste do Brasil. In: $42^{\circ}$ Reunião Anual da Sociedade Brasileira de Zootecnia; 25-28 jul 2005; Goiânia, GO. Goiânia: SBZ; 2005(1):1. 